EDITORIAL

\title{
DE FRENTE AL XIX CONGRESO ARGENTINO DE DIABETES
}

"A este respecto debo confesar mi prevención contra los datos científicos que en muchas ocasiones con su deficiencia perturban más que ayudan. Creo en la eficacia de utilizar como correctivo del dato numérico la constatación personal para que no ocurra lo que al espectador de fútbol que, con la radio a transistores pegada a la oreja, cree lo que dice el locutor con preferencia a lo que ven sus ojos"

Arturo Jauretche ${ }^{1}$

Como suele ocurrir en todas las familias como parte de nuestro crecimiento como individuos, tuve una vez una seria discusión con mis padres en relación a la especialidad que había decidido elegir. Corría el fin de la vapuleada década de los años 1970 y, con el título fresquito, todavía crujiente bajo el brazo, les hice saber que era mi intención dedicarme a la atención de los pacientes con diabetes, y hacer de esta enfermedad mi campo de investigación. Guiados obviamente por los sentimientos (ambos eran primero progenitores y luego profesionales de la salud), me dijeron, con cara de extrema preocupación: " ¡Cómo vas a especializarte en una enfermedad solamente, no te das cuenta que si se descubre la cura de la diabetes te vas a quedar sin trabajo!" Como todos sabemos, lamentablemente este temor dista hoy de ser una realidad y, peor aún, la diabetes mellitus constituye en la actualidad una fuente de preocupación y sufrimiento para una de cada diez personas adultas en nuestro país ${ }^{2}$ y una pesadilla para los sistemas de salud por las dificultades y costos inherentes a la atención de los casi 400 millones de individuos que la padecen a nivel mundial, y por los esfuerzos necesarios para evitar que un número similar de sujetos en riesgo la desarrolle en un futuro no lejano 3 .

Obviamente, simples deducciones basadas en estas alarmantes cifras y en la inequidad existente en nuestra sociedad nos podrían sumir en una profunda y casi pesimista preocupación, no ya en cuanto a las fallas en el acceso a la atención y a la provisión de medicamentos e insumos de un gran número de pacientes, sino mucho peor aún, en relación a la posibilidad de que una parte no despreciable de las personas atendidas predominantemente en el sector público esté expuesta a condiciones de inseguridad alimentaria ${ }^{4}$, careciendo de un acceso estable a una dieta segura, nutritiva y adecuada para su condición de pacientes con diabetes, aún tratándose de niños o mujeres embarazadas. Pero el pesimismo inmoviliza, y los editoriales pesimistas no atraen a los lectores. Demos un primer paso hacia el cambio reconociendo la existencia de esta dolorosa realidad y su carácter de asignatura pendiente.

Teniendo esto presente, pondremos nuestra mira en cómo cumplir con los objetivos establecidos en el estatuto de la Sociedad Argentina de Diabetes (SAD) en relación a fomentar el estudio, las investigaciones, la enseñanza y el intercambio de información sobre los distintos aspectos de la diabetes mellitus. Sin duda alguna, la herramienta fundamental para cumplir con estos fines es la realización del Congreso Argentino de Diabetes, actividad que la Sociedad lleva adelante ininterrumpidamente cada dos años desde 1978.

\section{¿Teoría, práctica, ambas o ninguna?}

En un planteo similar al realizado suspicazmente por Arturo Jauretche hace casi cinco décadas podemos decir, en base a una breve experiencia en la práctica médica, que el conocer (datos, hechos) no siempre lleva a saber qué hacer (en la práctica). Las enfermedades muchas veces escapan del molde planteado por las descripciones de los libros de texto, será porque, como decimos medio en broma medio en serio, los pacientes no los leyeron, más aún, sabiendo que el sujeto que intentamos ayudar con nuestros conocimientos y habilidades es único y muchas veces, irracional (como lo somos los médicos también).

Las referencias que utilizamos para tomar decisiones médicas provienen de la información básica (bioquímica, fisiología, fisiopatología, genética, psicología, antropología, etcétera) necesaria para entender los principios de su atención, y de las evidencias que guían de la forma más apropiada posible el diagnóstico y el tratamiento. Sin embargo, hasta las evidencias provenientes de la investigación clínica son a menudo, como decía Jauretche, perturbadoras por su inconsistencia, y permanentemente nos vemos obligados a descartar la información contenida en el ensayo clínico más actualizado y que habíamos considerado como "la última palabra" (en buena parte quizás porque la "torre de marfil" de los estudios clínicos dista mucho de la realidad cotidiana del consultorio) ${ }^{5}$. La cantidad de información disponible, aún proveniente de fuentes incontestables 
en cuanto a sus fines, puede tanto iluminar como confundir: la práctica diaria nos lleva a encontrar constantemente excepciones para cada lineamiento terapéutico, cada consenso, cada ensayo clínico controlado; son muchos los casos que nos confrontan día a día con la duda sobre lo correcto de las decisiones tomadas ${ }^{6}$.

Pero tampoco es posible guiar una práctica en base a tener simplemente "calle" o "estaño", como se decía otrora. No se pueden colocar los ladrillos que aporta el empirismo en el vacío, sin un armazón, un sustento o nexo dados por el conocimiento teórico. Una vez más, citando a Jauretche, “... el ratón de biblioteca, de hábitos sedentarios y anteojos gruesos, no es el más indicado para corregir el dato por medio de las observaciones, pero tampoco basta con mirar para ver"1.

Así es como la interpretación (reconociendo la señal por encima del ruido) y el establecimiento de prioridades que deben contemplar no sólo lo biológico, sino lo individual y social, nos llevan a veces a darnos cuenta de que lo que sostienen las evidencias y lo que es más conveniente para nuestro paciente no siempre van de la mano. Para Sackett y col., una buena práctica médica resulta de la integración del conocimiento de las mejores evidencias disponibles con la experiencia clínica y el respeto de los valores del paciente?. Podremos disentir con respecto al orden de preeminencia, pero en mi opinión el juicio clínico (la capacidad de tomar decisiones correctas frente a la incertidumbre), la empatía (con el consiguiente compromiso por el otro), la reflexión autocrítica, la curiosidad y la humildad en el intercambio de conocimientos son las características más relevantes de un buen profesional de la salud. Y de muchas de estas cosas, aplicadas al campo de la Diabetología, se trata este XIX Congreso Argentino de Diabetes.

\section{Parecido, pero distinto}

Con respecto a las actividades de intercambio de información de la SAD, si bien las "formas de presentación" son más o menos similares, el principio activo, o más bien su trasfondo, se ha venido modificando en los últimos años. Reflejo de esta modificación es, por ejemplo, la participación cada vez más activa de los Comités de Trabajo en el dictado regular de cursos, en la elaboración de lineamientos diagnósticos/ terapéuticos, y en forma orgánica en las Jornadas, el Congreso y las Reuniones Científicas ordinarias. Otro cambio cuali-cuantitativo se da a nivel del trabajo de los Capítulos, que despliegan una actividad cada vez más intensa, en muchos casos coronada por la realización de Jornadas Regionales de excelente capacidad de convocatoria y nivel académico, así como de especial importancia estratégica para poner en el tapete el problema que representa la diabetes a lo largo y ancho de la geografía de nuestro país. Evolución natural de este cambio centrífugo es la transformación de las Jornadas Regionales en instancias para la presentación de trabajos científicos originales que permiten a los socios adherentes adquirir la condición de titulares, y cuyos resúmenes se publican en el presente número de la revista de la SAD.

No voy a hablar en este comentario editorial del programa a desarrollar en el Congreso más que para decir que, a mi juicio, lo encuentro muy atractivo y balanceado (entre conocer y hacer, entre lo básico y lo clínico, entre lo establecido que es necesario fijar y lo novedoso que es conveniente adquirir), pero la razón de uno es la sinrazón de los otros (y viceversa), por lo que los asistentes tendrán la última palabra en este sentido. No quiero dejar de hacer partícipes a los lectores de mis felicitaciones a los miembros del Comité Científico por el encomiable y tesonero esfuerzo realizado en su confección, y a su Presidente por la afable, pero a la vez atenta y estricta conducción de esta prolongada tarea que se extendió por casi un año.

\section{Una breve conclusión}

Hay algo más que presta a este XIX Congreso de Diabetes un marco especial. No es sin embargo inherente al Congreso mismo sino al hecho de que el 28 de diciembre de este año se cumplen 60 años de la fundación de la Sociedad Argentina de Diabetes. El importante legado de sus fundadores, ya sea investigadores básicos o médicos clínicos de renombre, me ha permeado a través de sus sucesores, a quienes considero mis maestros. Por más breve que sea esta mención, mi agradecimiento para éstos, y mi reconocimiento para aquellos que constituyen elementos a los que asigno especial trascendencia dentro de este mensaje.

Concluyo este comentario con una vuelta a lo personal y es reconociendo el apoyo incondicional de mis seres queridos, mis amigos y mi familia que me acompañan en esta tarea, y agradeciendo a mi esposa Astrid porque es quien sabe (y casi siempre lo dice, menos en el caso de estos párrafos en cuya revisión obviamente no fue involucrada) cuándo debo borrar todo lo que escribí y empezar de nuevo.

Dr. Pablo Arias

Presidente de la Sociedad Argentina de Diabetes 


\section{REFERENCIAS}

1. Jauretche A. El medio pelo en la sociedad Argentina. Apuntes para una sociología nacional. A. Peña Lillo Editor, Buenos Aires, 1966, p. 4.

2. Ferrante D, Linetzky B, Konfino J, King A, Virgolini M, Laspiur S. Encuesta nacional de factores de riesgo 2009: evolución de la epidemia de enfermedades crónicas no transmisibles en Argentina. Estudio de corte transversal. Rev. Argent. Salud Pública, 2011; 2: 34-41.

3. International Diabetes Federation. IDF Atlas. http://www.idf.org/sites/default/files/EN_6E_Atlas_Full_0.pdf (fecha de acceso $26 / 09 / 2014)$.

4. Aguirre P. La seguridad alimentaria. http://www.econ.uba.ar/planfenix/docnews/III/Politicas\%20alimentarias/Aguirre.pdf (fecha de acceso 26/09/2014).

5. Sackett DL, Haynes RB, Guyatt GH, Tugwell P. Epidemiología clínica. Ciencia básica para la Medicina Clínica. $2^{\circ}$ Edición. Editorial Panamericana, Buenos Aires 1994; p. 249.

6. Del Mar C, Doust J, Glasziou P. Clinical thinking. Evidence, communication and decision-making. Blackwell Publishing, Malden, MA, USA 1996; p. 1.

7. Sackett DL, Rosenberg WM, Gray JA, Haynes RB, Richardson WS. Evidence based medicine: what it is and what it isn't. BMJ, 1996; 312: 71-72. 